\section{Change in Conservation Efforts}

As postdoctoral scholars in the field of conservation, we laud the empirically supported call of Arlettaz and colleagues (BioScience 60: 835-842) for conservation biologists to actively implement conservation recommendations and we offer further suggestions.

We believe that conservation scientists should begin grassroots change for gaining recognition within academia for implementation efforts. For example, in our curriculum vitaes we have a section that describes our efforts to implement our researchderived recommendations and the resulting impacts. We crafted this section because we believe that onthe-ground changes in conservation (in our case a regulatory change, revised marine park boundaries, and more than $\$ 100,000$ of programmatic grants with lasting, tangible conservation products) speak more to our success as conservation scientists than just publications. If more people list implementation and impacts on their curriculum vitaes and yearly activity reports; if search committees ask for statements of implementation; and if lab heads, department chairs, and deans give rewards and acknowledgment for implementation, a widespread change will occur. A rewards system does not need to be established by new rules; all that is required is bottom-up development of a common currency to create acceptance throughout academia.

The authors aptly described the common barriers to implementation of conservation guidelines and implied that the conservation community should focus more on relevant but often complex issues. We agree, but recognize that scientists' sphere of influence can be quite limited within these complex global issues. In cases when it is not possible to directly implement their recommendations, we urge conservation scientists to actively escort their recommendations through the established implementation processes. Active escorting can include serving on advisory boards, requesting observer status at international governance meetings, submitting letters during public comment periods, writing reports about recommendations specifically for the implementing agency, and offering to be a resource to the individual agency staffer(s) responsible for the implementation.

To facilitate this process, we suggest scientists begin building connections with managers and policymakers in early research stages - even before recommendations have been formulated-as it often takes considerable time to build the trust necessary to create relationships that will lead to lasting change. We additionally suggest building the time and travel costs for implemenation or active escorting into grant proposals; this establishes implementation as more than an afterthought that is conducted on piecemealed time and funds, but instead gives this important piece of conservation science a prominent and tangible place in research design and funding.

LEKELIA D. JENKINS

Lekelia D. Jenkins (kikij@uw.edu) is a David H. Smith Conservation Research Fellow at the University of Washington School of Marine Affairs.

SARA M. MAXWELL Sara M. Maxwell (sara.maxwell@ mcbi.org) is a postdoctoral fellow at the Marine Conservation Biology Institute and University of California Santa Cruz Long Marine Laboratory.

doi:10.1525/bio.2011.61.2.19

\section{Response from Arlettaz and Colleagues}

We agree with Jenkins and Maxwell that a fundamental change in assessment criteria would help move conservation biology beyond publications and toward an active discipline that places science within the policy and management realm. We also encourage all conservation researchers to highlight in their résumés how their scientific results have been implemented by policymakers and practitioners in the field, as well as the resulting impact on biodiversity. However, we doubt that this would be sufficient to overcome the immense research-implementation divide prevailing in biodiversity conservation, which partly stems from the practices currently ruling research institutions.

The reward system in academia for conservation scientistsisheavily focused on publications in peer-reviewed journals. Although we believe that peerreviewed research must be maintained, we think it is only one dimension of effective conservation science. Conservation biology differs from other disciplines among the life sciences in that it is mission driven. However, the consequential trade-off that conservation scientists face when ensuring that their scientific evidence is employed by policymakers and conservation practitioners is ignored by almost all research institutions when assessing academics for employment, promotion, or grant funding.

One first idea for trying to overcome this is developing a system of accreditation that rewards the full spectrum of activities that conservation biologists play, similar to the patent-based accreditation system of engineers. In addition to the bottom-up approach suggested by Jenkins and Maxwell, we propose top-down evaluation rules be recognized by academia. Indexes for biodiversity conservation impact similar to the traditional metrics estimating publications output must be developed.

A second idea is for new scientific journals or sections in existing conservation journals to publish results that are not simply novel but are proven to be useful for regional conservation in practice. In these sections, authors would provide a letter of support from practitioners demonstrating that their work is of practical importance, similar to the traditional approach of engineers for progressing relevant work in their field. Journals may also systematically request practitioners to function as reviewers for judging the applicability of results. Such concepts would tighten the collaboration between conservation scientists and practitioners, optimally from the start of the research process, 
as shrewdly suggested by Jenkins and Maxwell, and would promote novel implementation pathways where there is no "established implementation process" to "escort recommendations through."

We thank Jeffrey D. Camm, Guillaume Chapron, Liana Joseph, Rudi Suchant, and William J. Sutherland for sharing with us their views about the subject while preparing this reply.

RAPHAËL ARLETTAZ VERONIKA BRAUNISCH

MICHAEL SCHAUB

JAMES E. M. WATSON Raphaël Arlettaz (raphael.arlettaz@iee. unibe.ch) and Michael Schaub are with the Division of Conservation Biology, Institute of Ecology and Evolution, at the University of Bern, Switzerland, and the Swiss Ornithological Institute.

Veronika Braunisch is also with the

Division of Conservation Biology, Institute of Ecology and Evolution, at the University of Bern, Switzerland, and the Forest Research Institute of Baden-Württemberg in Germany.

James E. M. Watson is with Global

Conservation Programs, Wildlife

Conservation Society, in the Bronx,

New York, and the University of

Queensland, The Ecology Centre, in Queensland, Australia.

doi:10.1525/bio.2011.61.2.20

\section{Hope and Realism in Conservation Biology}

Swaisgood and Sheppard (BioScience 60: 626-630) have reminded us that hope is an essential component of effective conservation biology. Without this, conservation biologists lose credibility, the public loses interest, despair prevails among scientists, and only defeat is anticipated. These authors advocate better balance between realism and hope, and I offer two suggestions to help find that optimal balance.

Swaisgood and Sheppard focus on conservation of biodiversity. While saving biodiversity is indisputably a major element in the larger context of our species' environmental problems, reality demands that we emphasize how biodiversity concerns are entangled with the human predicament generally. In support of this enlarged context, my second suggestion is to compile two lists, one containing things that inspire hope and a second listing things that make hope (or optimism) difficult. With these lists, we can evaluate how our individual efforts contribute to improving the hope-to-despair ratio in the context of the conservation nexus as a whole. We also can suggest promising directions for future research (and funding). In this spirit, I offer the following preliminary lists.

Things that give reason for hope:

- human ingenuity

- increasing awareness of the human predicament among the world's peoples

- increasing awareness of this predicament among national and state governments

- many successful achievements by nongovernmental organizations and governments

- rapidly accumulating scientific knowledge of how ecological and social systems work

- increasing interest in ecologically based economics

- technological innovations relevant to conservation

- increasing pubic awareness of ecosystem services

- energy efficiency improvements

- development of sustainable energy sources

Things that give reason for despair:

- accelerating biodiversity losses

- the human ecological footprint now exceeds estimated biocapacity of the planet

- continuing human population growth with its inherent inertia

- human population growth remains a taboo topic for politicians

- increasing per capita food scarcity and declining fresh water supplies

- anthropogenic climate change

- threats of nuclear warfare
- threats of social disintegration

- growing demands for energy

- economic decline and corporate oligarchy

- increasing consumption per capita

- political polarization and government paralysis

- no politically viable alternative to the universal goal of rapid economic growth

- increasing ignorance of science

- decreasing support for higher education

- rising poverty coupled with increasing inequality of wealth distribution

- terrorism

- declining marine fisheries

- increase in infectious diseases

- growing complexity of the human enterprise requiring an increasing percent of resources devoted to maintenance

WILLIAM Z. LIDICKER, JR. William Z. Lidicker,Jr. (wlidicker@ berkeley.edu) is professor emeritus of integrative biology at the University of California, Berkeley.

doi:10.1525/bio.2011.61.2.21

\section{Reconnecting People to Nature Is a Prerequisite for the Future Conservation Agenda: Response from Swaisgood and Sheppard}

We welcome William Lidicker's thoughtful comments on balancing hope and realism. We are glad that our article is fulfilling its intended role of stimulating dialogue and we agree that taking stock of objective reasons for hope and despair will help move conservation goals forward. Clearly, there is more empirical reason for pessimism than hope, in Lidicker's list and in reality. Therefore, we caution against a literal balancing act between hope and despair. Fortunately, Lidicker did not take us down this path; instead, he suggests we use this equation to evaluate "how our individual efforts contribute to improving the hope-to-despair ratio." This is a useful metric as long as it is kept in proper perspective. 